\title{
Field and Laboratory-based Approach for the Determination of Friction Angle of Geological Discontinuities of Malaysian Granites
}

\author{
R. A. GHANI*, T. L. GOH, A. M. HARIRI AND Y. N. BAIZURA \\ Geology Programme, Faculty of Science and Technolgy, \\ Universiti Kebangsaan Malaysia, \\ 43600 UKM Bangi, Selangor, Malaysia
}

\begin{abstract}
The basic friction angle, $\Phi_{\mathrm{b}}$ for artificially sawn discontinuity planes for fresh granite, as determined by tilt testing, has an average value of $30^{\circ}$. For the natural rough discontinuity surfaces, a wide range of values have been determined for the peak friction angle, $\Phi_{\text {peak }}$ ranging from $47^{\circ}$ to a maximum value of $80^{\circ}$, depending on the joint roughness coefficient (JRC). The average values of the friction angles for the different degrees of roughness were as follows: JRC $2-4=58^{\circ} ; \mathrm{JRC} 6-8=60^{\circ}$; JRC $8-10=47^{\circ} ; \mathrm{JRC} 12-14=60^{\circ} ; \mathrm{JRC} 14-16=71^{\circ} ; \mathrm{JRC} 18-20=80^{\circ}$.
\end{abstract}

Key words: tilt testing; peak friction angle; roughness coefficient; stability; rock masses; comparison; estimation

The surface roughness and frictional properties of geological discontinuity surfaces play an important role in assessment of the stability of rock masses, for example in underground excavation and in particular for cut rock slope stability assessment. This surface roughness can be expressed as the coefficient of friction or the friction angle of the rough discontinuity surface. However quantification of this parameter has generally been neglected in Malaysia and the results presented here are the findings of a recently conducted systematic study of this parameter. While sophisticated and costly, laboratory machines involving complicated testing procedures exist for determination of the shear strength of discontinuities from which the friction angle can be determined. The approach adopted in this research was to apply relatively low cost and easy applicable methods to quantify the friction angle of the discontinuity plane surfaces for the findings to attain wider applications. Hoek (2007) with over forty years experience in rock mechanics, recently recommended this approach because a larger number of tests can be conducted; mean values and their range can also be determined, and the interpretation of the results can better represent the site conditions. The tilt test has been employed to determine the angle of friction of both natural as well as artificially prepared sawn discontinuity surfaces for fresh to slightly weathered granite. The testing procedures closely follow the recommendations of Priest (1993). The joint roughness coefficient (JRC) as defined by Barton and Choubey (1977) is measured in the field as well as in the laboratory. A comparison of these two findings presents the possibility of estimation of the friction angle of the discontinuity plane surfaces based on JRC which can be rapidly determined during a field survey.

\section{MATERIALS AND METHODOLOGY}

Basically two approaches have been applied for the determination of friction properties of the

\footnotetext{
* Corresponding author (e-mail: aghani@ukm.my)
} 
discontinuity surfaces: a field and laboratory determination of JRC as defined by Barton and Choubey (1977); and tilt testing of both natural and artificially prepared sawn discontinuities in accordance to the procedures outlined by Priest (1993). Fresh and slightly weathered granite rock blocks collected from the different sites were cut into approximately $6 \mathrm{~cm}$ cubic pieces which were then sawn into two pieces to obtain the artificial discontinuity surfaces. In addition, at each site a systematic discontinuity survey was conducted to characterise the rock mass. In this survey, the surface roughness of the naturally occurring discontinuity surfaces was determined using a profiler such as the one shown in Figure 1.

During the field survey, matched pairs of rock material blocks containing natural discontinuities with different JRC values were also collected. Both the sawn pieces as well as the naturally occurring discontinuities with different degrees of roughness were subjected to tilt testing using the self-fabricated simple testing apparatus shown in Figure 2. In this manner, both the basic friction angle, $\Phi_{\mathrm{b}}$ obtained for the artificially sawn surfaces, as well as the peak friction angle, $\Phi_{\text {peak }}$ for the natural surfaces with different degrees of roughness were determined.
For this investigation, field surveys and sampling were conducted at four different sites underlain by granite as follows:

- Kajang Rock Quarry, Kajang, labelled as KR,

- SILK Highway, Kajang, labelled as SH,

- Pos Selim to Kg.Raja road, labelled as PS; and

- Bukit Penggorak Quarry, Kuantan, labelled as BP.

Figure 3 shows the locations of the investigated sites.

\section{RESULTS AND DISCUSSION}

A summary of the results of tilt testing of artificial and natural discontinuities as well as the JRC values for the investigated granite discontinuities are presented in Table 1.

The following points can be summarised from the results of this investigation:

- For the sawn surfaces, the artificially prepared discontinuities, the friction angle for both the fresh as well as the slightly weathered surfaces were within the same range of overlapping values. This result indicated that slight weathering did not cause a

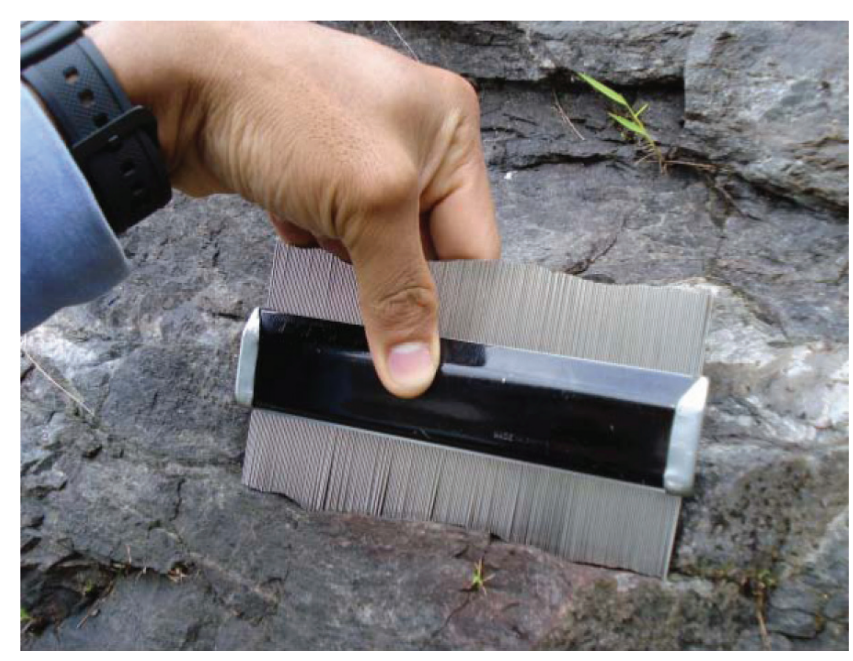

Figure 1. Profiler employed for the determination of JRC. 


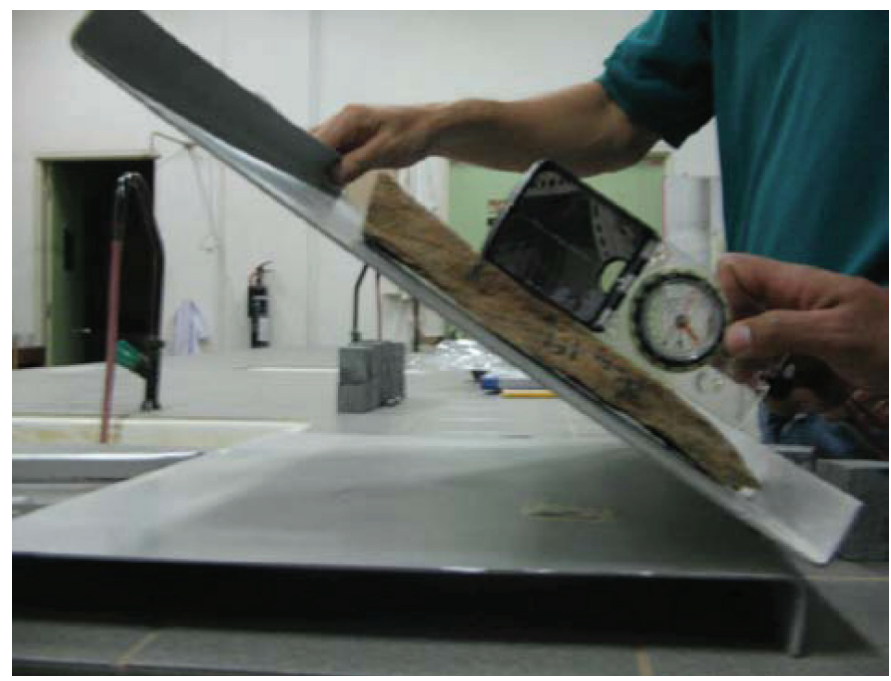

Figure 2. Simple tilt test apparatus for determination of peak friction angle, $\Phi_{\text {peak }}$ of naturally occurring discontinuities.

Table 1. Mean values and range for friction angles of geological discontinuities of investigated granites.

\begin{tabular}{l|cccccccc}
\hline $\begin{array}{c}\text { Discontinuity } \\
\text { roughness }\end{array}$ & $\begin{array}{c}\text { Sawn surface } \\
\text { (Fresh) }\end{array}$ & $\begin{array}{c}\text { Sawn surface } \\
\text { (Slightly } \\
\text { weathered) }\end{array}$ & $\begin{array}{c}\text { JRC } \\
2-4\end{array}$ & $\begin{array}{c}\text { JRC } \\
6-8\end{array}$ & $\begin{array}{c}\text { JRC } \\
8-10\end{array}$ & $\begin{array}{c}\text { JRC } \\
12-14\end{array}$ & $\begin{array}{c}\text { JRC } \\
14-16\end{array}$ & $\begin{array}{c}\text { JRC } \\
18-20\end{array}$ \\
\hline $\begin{array}{l}\text { Mean angle }\left[{ }^{\circ}\right] \\
\text { Range }\left[^{\circ}\right]\end{array}$ & 30.10 & 29.90 & 58.30 & 59.70 & 47.30 & 59.70 & 70.80 & 79.90 \\
\hline
\end{tabular}

reduction in the surface roughness of these surfaces. In other words, slight weathering of the rock did not cause sufficient deterioration of the rock material surface to result in a decrease in its surface roughness.

- Generally stated, discontinuities with higher JRC values had higher friction angles. However, for a given JRC value, the range of friction angle values from tilt testing could have a wide range of up to ten degrees.

- Within a given granitic rock mass, for example Kajang Rock Quarry, different JRC values where determined for different discontinuity sets. In the Kajang Rock Quarry for example, for the different discontinuities sets, the JRC values of $2-4,6-8,8-10,12-14$ and 18-20 were determined. This finding indicated the importance of the inclusion of JRC measurement during field discontinuity surveys and the determination of JRC for specific discontinuity sets.

From Table 1, the basic friction angle, $\Phi_{\mathrm{b}}$ for the tested granites was determined as $30^{\circ}$. Depending on the degree of roughness, the peak friction angle, $\Phi_{\text {peak }}$ attained a maximum value of $80^{\circ}$ depending on the JRC value. These findings are in general agreement with studies by other researchers, for example Barton (1976), Barton and Choubey (1977) and Hoek and Bray (1981). This study also illustrates the 


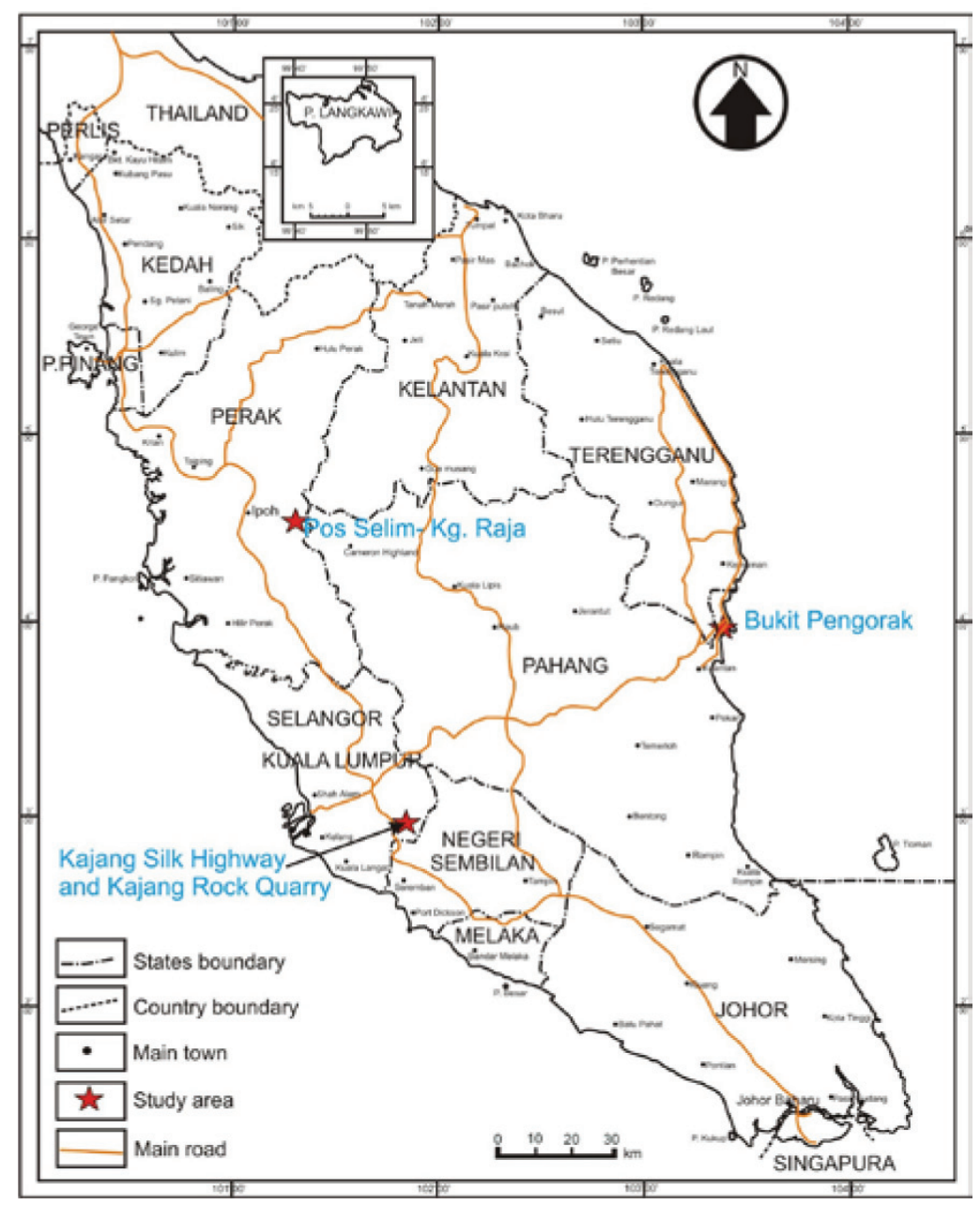

Figure 3 Location of investigated sites.

importance of the determination of JRC values as a means of estimating the friction angle of discontinuity surfaces in the field based on the establishment of a qualitative correlation such as the one presented in this study (Table 1). Similar studies are currently being undertaken for the other major lithologies in Malaysia.

\section{CONCLUSION}

The basic friction angle $\Phi_{\mathrm{b}}$ for granite was determined as $30^{\circ}$ and the peak friction angle $\Phi_{\text {peak }}$ varied from $47^{\circ}$ to as high as $80^{\circ}$ depending on the roughness of the discontinuity surface as shown by its JRC. Determination of JRC in the field could be employed to estimate the friction angle of the discontinuity plane surfaces for the granitic rock masses.

\section{ACKNOWLEDGEMENTS}

This research was funded by the research grant UKM-ST-FRGS 0023-2007 of the Government of Malaysia, which is gratefully acknowledged. The authors also acknowledge the support of the staff and facilities at the programme and faculty.

Date of submission: September 2011 Date of acceptance: October 2011 


\section{REFERENCES}

Barton, N 1976, 'The shear strength of rock and rock joints', Journal of Rock Mechanics, Min. Sci. \& Geomechanics, vol. 13, no.9, pp. 255-279.

Barton, N \& Choubey, V 1977, 'The shear strength of rock joints in theory and practice', Rock Mechanics, vol. 10, pp. 1-54.
Hoek, E 2007, Practical rock engineering. Course notes, Hoek Corner, <http://www.rocscience. com>.

Hoek, E \& Bray, JE 1981, Rock slope engineering, 3 edn, Inst. Min. Metall: London.

Priest, SD 1993, Discontinuity analysis for rock engineering, 1st edn, Chapman \& Hall. 